\title{
Commentary: From Mental Health to Mental Wealth in Athletes: Looking Back and Moving Forward
}

\author{
Ian Sherwin * \\ Department of Physical Education and Sport Sciences, University of Limerick, Limerick, Ireland
}

Keywords: mental health, stigma, elite sport, intrinsic motivation, coach education

\section{A commentary on}

From Mental Health to Mental Wealth in Athletes: Looking Back and Moving Forward by Uphill, M., Sly, D., and Swain, J. (2016). From Mental Health to Mental Wealth in Athletes: Looking Back and Moving Forward. Front. Psychol. 7:935. doi: 10.3389/fpsyg.2016.00935

\section{OPEN ACCESS}

Edited by:

Sergio Machado,

Federal University of Rio de Janeiro,

Brazil

Reviewed by:

Bruno Oliveira,

Federal University of Rio de Janeiro,

Brazil

Martin James Turner,

Staffordshire University, UK

Amber Mosewich,

University of Alberta, Canada

${ }^{*}$ Correspondence:

lan Sherwin

ian.sherwin@ul.ie

Specialty section:

This article was submitted to Movement Science and Sport

Psychology,

a section of the journal

Frontiers in Psychology

Received: 12 February 2017 Accepted: 21 April 2017

Published: 10 May 2017

Citation:

Sherwin I (2017) Commentary: From Mental Health to Mental Wealth in Athletes: Looking Back and Moving Forward. Front. Psychol. 8:693. doi: 10.3389/fpsyg.2017.00693
The mini-review by Uphill et al. highlights the prominence of psychological issues in sport through various media. The review also highlights gaps in the research in conceptions in mental health, interventions needed, and collaborative work that remains outstanding. The review used the Keyes (2002) model as a framework in which athlete well-being and mental health can be readily understood. Although the incidence of mental health difficulties are similar in athletes to the general population the article also draws reference to the existing stigma of mental health and the under-recognition of mental illness in sporting populations. This may be as a result of not wishing to be seen as showing weakness in a culture that perceives athletes as being mentally "tough." This article focuses on athletes; however, it is important to look beyond athletes as we should be at least as concerned with coaches' well-being as athletes.'

A coach ill-equipped to deal with their own psychological issues may see a change in their coaching behavior which may impact their performance in training and competitive situations. A potential consequence of this would be an increase in negative coaching behaviors (e.g., feedback highlighting athlete mistakes) which may impact their athletes (Badami et al., 2011). High levels of intrinsic motivation are linked to enhanced mental health (Ryan and Deci, 2000). It is known from previous research that coaches who display positive, supportive behaviors increase intrinsic motivation in their athletes (Amorose and Horn, 2000). Conversely, athletes who perceived their coach to display more autocratic behaviors produced lower levels of intrinsic motivation (Hollembeak and Amorose, 2005). Further, the club director-coach (employeremployee) relationship may carry similar interactions that may affect intrinsic motivation in coaches. Previous research in human resources (Boxall et al., 2015) indicates employees who perceive their expectations have been met by employers have a higher level of job satisfaction and are more intrinsically motivated.

While there is advocacy for mental health support services for athletes, evidence of similar services for coaches is scarce. Sebbens et al. (2016) developed a 4-h applied workshop designed to upskill and educate people who work in high performance sport on Mental Health for coaches in Australia which has shown a positive effect on coaches' knowledge of psychological well-being. Even a brief intervention can be effective in increasing coaches' mental health literacy and confidence in helping an athlete in an elite performance setting. Coach-athlete relationships have been deemed essential to effective coaching (Felton and Jowett, 2013). Coaches with a mental health issue (for example, stress) would be predicted to react differently to players' issues at that time which may influence the coach-athlete relationship. For example, should an athlete suffer a career-threatening 
injury the coach may not have the psychological resources to provide social support to the player if their own well-being is under threat. In contrast, coaches who appraise stress as a challenge are more likely to offer social support to their athletes (Dixon et al., 2016). Similarly there may be unforeseeable factors such as a bereavement that may have a significant impact on the mental health of the entire squad or group. In November 2016, a tragic air accident in South America left few survivors but among them were players and management from the Brazilian Chapecoense soccer team who lost friends, colleagues, and relatives in the ill-fated flight, LMI2933. Where would an incident such as this leave the coaches and players on the spectrum of mental health and well-being? These situations underline the importance of including mental health training in coach education courses so that coaches can have an understanding not just of psychological skills but also of mental health literacy (Sebbens et al., 2016) for themselves, athletes, and others involved in sport.

Coaches are typically hired to achieve an improvement on past team performance (Pierce et al., 2017), rather than to advance the well-being of their players. Thus, it is not surprising that "dark sides" or Machiavellian characteristics may be prominent among successful leaders and coaches (Judge et al., 2009). A coach who displays Machiavellian traits may be more likely to be positioned in the upper left quadrant of the Keyes (2002) model and with support may shift to the right as these traits diminish in favor of a more autonomysupportive coaching climate. Similarly a coach who is supportive and empathic with athletes and positioned in the upper right quadrant could experience external factors that affect their mental health and fluctuate across the continuum. Coaches who are empathic toward their athletes create an environment of open

\section{REFERENCES}

Amorose, T., and Horn, T. (2000). Intrinsic motivation: relationships with collegiate athletes' gender, scholarship status and perceptions of their coaches' behaviour. J. Sport Exerc. Psychol. 22, 63-84. doi: 10.1123/jsep.22.1.63

Badami, R., VaezMousavi, M., Wulf, G., and Namazizadeh, M. (2011). Feedback after good versus poor trials affects intrinsic motivation Res. Q. Exerc. Sport 82, 360-364. doi: 10.1080/02701367.2011.10599765

Bauman, N. J. (2016). The stigma of mental health in athletes: are mental toughness and mental health seen as contradictory in elite sport? Br. J. Sports Med. 50, 135-136. doi: 10.1136/bjsports-2015-095570

Boxall, P., Hutchison, A., and Wassenaar, B. (2015). How do high-involvement work processes influence employee outcomes? An examination of the mediating roles of skill utilisation and intrinsic motivation. Int. J. Hum. Resour. Manage. 26, 1737-1752. doi: 10.1080/09585192.2014.962070

Collins, D., McNamara, A., and McCarthy, N. (2016). Putting the bumps in the rocky road: optimizing the pathway to excellence. Front. Psychol. 7:1482. doi: 10.3389/fpsyg.2016.01482

Coyle, M., Gorczynski, P., and Gibson, K. (2017). "You have to be mental to jump off a board any way": elite divers' conceptualizations and perceptions of mental health. Psychol. Sport Exerc. 29, 10-18. doi: 10.1016/j.psychsport.2016. 11.005

Dixon, M., Turner, M. J., and Gillman, J. (2016). Examining the relationships between challenge and threat cognitive appraisals and coaching behaviours in football coaches. J. Sports Sci. doi: 10.1080/02640414.2016.1273538. [Epub ahead of print]. communication and communicate more effectively (MacIntyre, 2015).

Creating a positive coaching climate and a positive organizational culture (Fletcher and Wagstaff, 2009) must include prioritizing coaches' well-being. Uphill et al.'s (2016) synthesis highlights the upsurge in research on mental health in elite sport (Bauman, 2016; Gucciardi et al., 2016; Rice et al., 2016; Coyle et al., 2017). A gap remains in the research literature which has yet to systematically address mental health in coaches and coaches' understanding of mental health issues in their athletes. Previous research on athlete pathways has shown the need for resilience in athletes as the pathway to performance level is never smooth (Collins et al., 2016). Coaches must have an understanding of the issues that may affect an athlete who perhaps has been deselected from a squad, not selected to start or is struggling with performance. Consequently there is a need for coach educators to address these issues as a priority.

There is an opportunity to present a short intervention such as that alluded to in Sebbens et al. (2016) in all coach education courses which will address both the well-being of coaches and equip them with a basic understanding of athlete mental health issues. Despite a number of high profile tragedies in sport there has been a tendency to downplay the significance of mental health issues (Reardon and Factor, 2010). Support for coaches should be in place not just to address mental health issues but to promote positive mental health within an environment in which a coach can flourish.

\section{AUTHOR CONTRIBUTIONS}

The author confirms being the sole contributor of this work and approved it for publication.
Felton, L., and Jowett, S. (2013). "What do coaches do" and "how do they relate": Their effects on athletes' psychological needs and functioning. Scand. J. Med. Sports Sci. 23, 130-139. doi: 10.1111/sms. 12029

Fletcher, D., and Wagstaff, C. (2009). Organizational psychology in elite sport: its emergence, application and future. Psychol. Sport Exerc. 10, 427-434. doi: 10.1016/j.psychsport.2009.03.009

Gucciardi, D. F., Hanton, S., and Fleming, S. (2016). Are mental toughness and mental health contradictory concepts in elite sport? A narrative review of theory and evidence. J. Sci. Med. Sport. 20, 307-311. doi: 10.1016/j/jsams.2016.08.006

Hollembeak, J., and Amorose., A. (2005). Perceived coaching behaviours and college athletes' intrinsic motivation: a test of self-determination theory. J. Appl. Sport Psychol. 17, 20-36. doi: 10.1080/104132005909 07540

Judge, T. A., Piccolo, R. F., and Kosalka, T. (2009). The bright and dark side of leader traits: a review and theoretical extension of the leader trait paradigm. Leader. Q. 20, 855-875. doi: 10.1016/j.leaqua.2009.09.004

Keyes, C. L. (2002). The mental health continuum: from languishing to flourishing in life. J. Health Soc. Behav. 43, 207-222. doi: 10.2307/3090197

MacIntyre, T. (2015). "Sustainable performance with empathy," in Leadership in Sport, eds P. Cummins, I. O’Boyle, and D. Murray (London: Routledge), 228.

Pierce, D. A., Johnson, J. E., Krohn, B. D., and Judge, L. W. (2017). Who should we hire: examining coaching succession in division I women's basketball. Int. J. Sports Sci. Coach. 12, 151-161. doi: 10.1177/17479541176 94732 
Reardon, C. L., and Factor, R. M. (2010). Sport psychiatry: a systematic review of diagnosis and medical treatment of mental illness in athletes. Sports Med. 40, 961-980. doi: 10.2165/11536580-000000000-00000

Rice, S. M., Purcell, R., De Silva, S., Mawren, D., McGorry, P. D., and Parker, A. G. (2016). The mental health of elite athletes: a narrative systematic review. Sports Med. 46, 1333-1353. doi: 10.1007/s40279-016-0492-2

Ryan, R. M., and Deci, E. L. (2000). Self-determination theory and the facilitation of intrinsic motivation, social development, and well-being. Am. Psychol. 55:68. doi: 10.1037/0003-066X.55.1.68

Sebbens, J., Hassmen, P., Crisp, D., and Wensley, K. (2016). Mental Health in Sport (MHS): improving the early intervention of knowledge and confidence of elite sport staff. Front. Psychol. 7:911. doi: 10.3389/fpsyg.2016.00911

Uphill, M., Sly, D., and Swain, J. (2016). From mental health to mental wealth in athletes: looking back and moving forward. Front. Psychol. 7:935. doi: 10.3389/fpsyg.2016.00935
Conflict of Interest Statement: The author declares that the research was conducted in the absence of any commercial or financial relationships that could be construed as a potential conflict of interest.

The reviewer $\mathrm{BO}$ and handling Editor declared their shared affiliation, and the handling Editor states that the process nevertheless met the standards of a fair and objective review.

Copyright (c) 2017 Sherwin. This is an open-access article distributed under the terms of the Creative Commons Attribution License (CC BY). The use, distribution or reproduction in other forums is permitted, provided the original author(s) or licensor are credited and that the original publication in this journal is cited, in accordance with accepted academic practice. No use, distribution or reproduction is permitted which does not comply with these terms. 